\title{
Effects of Problem-Solving Technique on Test Anxiety and Academic Performance among Secondary School Students in Ondo State
}

\author{
Dr. Olorunfemi-Olabisi, F.A. \\ Department of Guidance and Counselling, Faculty of Education, Adekunle Ajasin University, Akungba-Akoko, \\ Nigeria.
}

\begin{abstract}
This study investigated the effects of problem-solving technique on test anxietyand academic performance of secondary school students.The study adopted a quasi- experimental pre-test post-test research method. Four nullhypotheses were generated and tested at 0.05 level of significance. Forty students identified with high anxiety level were selected for the study. The selected samples were grouped into experimental and control groups. ATestAnxiety Scale developed by the researcher and validated was used for the study. The questionnaire was administered to identify students' level of test anxiety before and after the treatment.The experimental group was taken through eight weeks of sixteen sessions of problem-solving therapy. Data collected were analyzed using mean, standard deviation and t-test. The results revealed there was significant difference in the test anxiety levels between groups. Also there was improvement in the academic performance of students in the experimental group who received the therapy. Based on these findings, it was concluded that problem-solving technique is effective in reducing testanxiety levels among students.
\end{abstract}

Keywords: Problem-solving, anxiety, test, academic performance

\section{Introduction}

The environment we are living in is physically, mentally, emotionally, socially and morally dynamic and challenging. We possess effective mechanism to meet every day stress. Sometime, normal adaptive mechanism can be over-activated and, thus, become maladaptive.A common outcome of such over-activation is anxiety(Spinella, 2001).Anxiety is complex and mysterious, as Freud realized many years ago. Anxiety, as an emotional component of human beings, manifests itself in life endeavorsin form of worries and restlessness. People are beset by intense feelings every day because lifecontinuously poses problems which every person strives to find solution to.

According to Barlow (2002), anxiety is a negative mood state characterized by bodily symptoms of physical tension and apprehension about the future. It is a psychological problem characterized by somatic emotional, cognitive and behavioural components. Anxiety is a general term for several disorders that cause nervousness, inability to sleep, apprehension and worrying. These disorders affect how we feel and believe, and they can manifest real physical symptoms. Mild anxiety is vague and unsetting, whilesevere anxiety can be extremely debilitating having a serious impact on a daily life.

Corey (1995), viewed anxiety as a learned response to situations that threaten an individual's security and self-esteem. Numerous studies conducted by scholars in the United State of America, Britain, Nigeria and some other parts of the world on anxiety (Spielberg,1972; Barlow, 2002 andD'Zurilla, 1988; Olorunfemi, 2010) can be found in literature.

According to Mischel (1971), anxiety is believed to be a pattern of behavior which occurs in response to cognitive or environmental stimuli resulting into changes in the rate of heartbeat, blood pressure and somatic motor behaviors such as trembling, stuttering and so on. Students are often confronted with lots of mental task that cause anxiety especially at examination or test periods. When this kind of emotional component manifests with regard to a test or examination condition, it is then regarded as test anxiety.

Busari and Uwakwe, (2001) affirmed that victims of extreme anxiety are not able to think of solution or adaptation to their immediate problem.

\section{Test anxiety}

According to literature, many definitions of test anxiety exist. Seipp (1991) defined test anxiety as an individual's physiological, cognitive and behavioural responses that stimulate negative feelings about an evaluation. When an individual experiences test anxiety, these physical and cognitive responses may lead to negative feelings and cognitions about testing situations.

According to Olatoye and Afuwape (2003) test anxiety is the physiological state of mind of a candidate about a test as expressed by the level of worry, fear, uncertainty, concern and helplessness expressed 
before, during or even after a test or examination. When an individual becomes anxious, the physiological system becomes aroused, such as the heart beating faster or the sweat glands producing more perspiration. At the same time the person may experience a higher sense of inadequacy.

Okatahi (2006) ascertained that students are often confronted with lots of mental tasks that cause anxiety especially during test or examination periods. Test anxiety as an emotional reaction of students in testing situation has been identified by psychologists as a determinant of academic performance. Such emotional state is accompanied with feelings of inadequacy, helplessness, heightened somatic reaction, anticipation of punishment and loss of status.

Causes

According to Barlow (2002), anxiety is caused by both internal and external stimuli. The internal stimuli compose of feelings of thoughts and events and what goes on around. External stimuli compose of environmental situations which give some concern of fear which cover general events about life (Morakinyo, 2005). Oresanya (2007) affirmed that anxiety may also arise when there is frustration occurring in some major life problems related to vocational, educational or adjustment. Excessive test anxiety may occur when the teachers threaten the students with a test.

Spielberger and Sarason, (1989) stated other factors that contribute to the development of test anxiety, among which are; self concept, self- awareness, self-image, peer factors and so on. If an individual's experience is negative, then the test anxiety level will be higher leading to lower performance. Consequently, if an individual's experience is positive, then, the test anxiety level will be lower leading to higher performance. Above all, it is important to consider motives, aptitudes, cognitive assessment of the task and past experience when analyzing test anxiety and how it relates to performance.

Although, Akinboye (1982 and Adeyoju (1989) in their studies investigated the causes of academic failure among students. They identified faulty or defective study skills, lack of self- control, and in-appropriate method of preparation for test and examinations as factors responsible for academic failure.

\section{Effects}

Mckeachie, Lin and Holinger (1991); Culler and Holahan (1980); Ryan (2001)and Sarason (1980) highlighted the inhibitive effect of test- anxiety on academic performance.Theirviews affirmed that high anxious students have been found to perform more poorly on cognitive demanding task than less test anxious subjects especially when performance condition is evaluative. During difficult task in which evaluative stress is present, low test anxious students tend to achieve better than high test anxious students. They noted that high test anxious students are dexterously affected by conditions such as achievement-orienting instruction. This is in agreement with Seipp, (1991) in the study of the relationship between anxiety and academic performance among students that test anxiety usually produce lower test performance. Also in agreement are Birenbaum and Pinck (1997) studies that showed low performance of highly anxious students which was as a result of inadequate preparation for test and examination.

According to D'Zurilla (1988), solutions must be implemented and the consequences of one's choice evaluated. Problem-solving strategy includes self-monitoring, self-control, self-reward, self-statement, self-talk etc. the basic idea of self-management interventions is that change can be brought about by teaching coping skills in problematic situations. The technique concerned itself with teaching people the skills they will need to manage their own lives effectively.

Training in effective test-taking skills could compensate for deficit caused by test-anxiety because it is a natural self-reaction to learn. Numerous authors have used several therapies such as cognitive restructuring (Adeyoju, 1989: Hassan and Okatahi, 1990), study skills training (Okatahi, 2006),relaxation technique(Yusuf,2008), self-monitoring technique (Osiki and Buhari,2006) have been found to reduce test anxiety. The results on the previous studies and the need to explore problem-solving training, method of reducing test-anxiety necessitated this study.

A realistic view of the world around us reveals the fact that human beings are continually confronted with situational problems which he or she must solve in order to maintain an adequate level of effective functioning.

Problem-solving as defined by D,Zurilla and Goldfried (1986), is a cognitive activity aimed at changing a problem from a given state to the goal state. Problem solving technique is cognitive because it occurs within the problem solver and can only be inferred from the problem solver's action.According to Mayer, (1994) problem solving can sometimes be used interchangeably with thinking and cognition. Inductive and deductive reasoning can be seen as part of sub-categories within the broad category of problem-solving.

Problem-solving as a behavior therapy involves learning, how to size up the different characteristics of problems, gather data on the problem, and clarify their severity. Skills are there-by developed concerning formulating reasonable problem-solving goals, generating alternatives solutions and selecting from the alternatives. In problem-solving program, decisions are made concerning specific behaviour to be controlled or 
changed. Examples are control of smoking, drinking, drug addiction, time-management, learning, study skills and dealing with obesity and over eating.

It is observed that a major reason for students not attaining their goals is the lack of certain skills or unrealistic expectations of change. It is in this vein that problem-solving techniquetrainingis to be provided as aguideline and a plan that will lead to change, thus, the need for this study. Based on the above assumptions, this study is to determine the effect of problem- solving technique in reducinglevel of anxiety among students,andto enhance academic performance.

\section{Purpose of the Study}

The main purpose of the study is to determine the effect of problem-solving technique on test anxiety and academic performance of senior secondary school students in Ondo State, Nigeria.

\section{Research Design}

The research design adopted for the study was quasi-experimental that employed pre-test/post-test experimental and control groups.

\section{Population}

The target population was all senior secondary school students in Ondo State, Nigeria.

\section{Sample and Sampling Technique}

A total number of forty students identified with high level of test anxiety were selected for this study. Twenty students (ten males and ten females) were designated into experimental and control groups. Samples were selected using purposive sampling technique.

\section{Instrument}

The instrument used for the study wasaself-developed questionnaire titled Test Anxiety Scale (TAS). The instrument was divided into two sections A and B. Section A consisted of items on demographic data of the respondents such as name of school, class, age, and sex. Section Bcontained 20 items describing different forms of feelingsleading totest anxiety. The items focus onfour major feelings such as; social humiliation, self-image, physiological hyper arousaland unpreparedness. The instrument was administered on the sample tocollect data on the study.The respondents were to indicate their degree of agreement to each item by ticking out one of the options provided; which areStrongly Agree $(\mathrm{SA})=4$, Agree $(\mathrm{A})=3$, Disagree $(\mathrm{D})=2$ and Strongly Disagree $(\mathrm{SD})=1$. To determine their level of anxiety, scores within $41-80$ in the scale were considered to be high while 1-40 were consideredto be low level of anxiety respectively. Only students within the score of 41-80 identified with high level of anxiety were selected and grouped into Experimental and Control groups for the study. In order to determine the academic performance, a teacher made test was conducted for the pretest and post test. The outcome of the post test result confirmed the effectiveness of the therapy.

\section{Validity of the instrument}

The instrument was validated by the researcher and test experts in counseling. The instrument was refined to meet face and content validity. The validity index of the instrument was 0.82 .This value attest to the validity of the instrument.

\section{Reliability of the instrument}

The reliability of the instrument was established through the test- retest method. The instrument was administered twice with an interval of two weeks on 20 students that were not part of the samplebut identified with high level of test anxiety. The two sets of scores from the responses were correlated using Pearson Product Moment Correlation method with a reliability coefficient of $r=0.87$. The value obtained attest to the reliability of the instrument.

Hypotheses

The following hypotheses were generated for the study:-

1. There is no significant difference in the test anxiety level mean score of subjects exposed to problemsolving technique and control group.

2. There is no significant difference in the academic performance of subjects exposed to problem-solving technique and control group.

3. There is no significant difference in the test anxiety post-test mean score of male and female subjects exposed to problem-solving technique 
4. There is significant difference in the academic performance post-test mean score of male and female subjects exposed to problem-solving technique.

\section{Procedure for treatment}

The procedure for treatment was carried out in three phases. Phase one was the pre-test phase where theTest Anxiety Scale (TAS) was administered to all the samples both experimental and control groups to collect data on their present level of anxiety. The respondents were to indicate their degree of agreement by ticking out one of the options provided; which are, Strongly Agree (SA), Agree (A), Disagree (D) and Strongly Disagree (SD). The responses were analyzed to confirm the levelof anxiety of the respondents.

Phase two was the treatment phase conducted in 16 sessions. The problem-solving training technique ran for eight weeks. Each week had two sessions (16 sessions) of two (2) hours per session. The selected students were classified into two groups of 20 students each; the experimental and control groups. The experimental group was exposed to problem-solving technique training. Within the treatment sessions, the experimental group were trained in problem-solving technique following the five steps model technique by D'zurilla and Goldfried (1988) to reduce test anxiety.These are:(i) Orientation,(ii) Problemdefinition, (iii) Generalization of ideas, (iv) Selection of options and (v)Implementation/ Evaluation. At the end of each step, participants were appropriately evaluated.

Phase three, was the post treatment phase. This phase was devoted to completing the test anxiety questionnaire after the treatment sessions. The TAS was administered and the achievement test (post-test) was conducted on the two groups (experimental and control).The responses were appropriately scored and subsequently used in the data analysis. Mean, standard deviation and t-test analyses were employed to determine the results.

This is mainly to determine the effectiveness of the therapy in reducing students anxiety level and improving their academic performance.

\section{Results}

The results of the findings are presented in the following tables.

Hypothesis 1.There is no significant difference in the test anxiety level means score of students' exposed to problem-solving technique and control group.

Table 1: Summary of t-test analysis on test anxiety levels (post-test) experimental and control groups

\begin{tabular}{|l|l|l|l|l|l|l|l|}
\hline Variables & No & $\mathrm{X}$ & SD & df & t-cal. & t-crit. & P \\
\hline Experimental & 20 & 28.70 & 10.20 & 38 & 4.10 & 2.02 & 0.05 \\
\hline Control & 20 & 51.80 & 7.85 & & & & \\
\hline
\end{tabular}

The result on table 1 revealed a t-test significant difference in test anxiety levels of experimental and control group at $\mathrm{t}$-cal $-4.10 . \mathrm{df}=38 \mathrm{t}$-crit. $2.02(\mathrm{p}<0.05)$. Since the $\mathrm{t}$-cal is greater than $\mathrm{t}$-crit 2.0 the hypotheses is rejected. This indicates that there is significant difference in the level of anxiety between the experimental and control group.

Hypothesis 2: There is no significant difference in the academic performance of subjects exposed to problemsolving technique and control group.

Table 2: Summary of t-test for academic performance(post-test) of experimental and control groups

\begin{tabular}{|l|l|l|l|l|l|l|}
\hline Variables & No & X & SD & df & t-cal & t-crit \\
\hline Experimental & 20 & 11.5 & 1.86 & 38 & 2.62 & 2.021 \\
\hline Control & 20 & 9.25 & 2.05 & & & \\
\hline
\end{tabular}

Table 2 indicated that there is significant difference in post -test mean scores in academic performance of experimental and control group at $\mathrm{t}$-cal $2.62 \mathrm{t}$-critical 2.02 at $\mathrm{df}=38(\mathrm{P}<0.05)$. $\mathrm{t}$-cal is greater than $\mathrm{t}$-critical therefore, the hypotheses which states that there is no significant difference in the academic performance of experimental and control group is rejected.

Hypothesis 3: There is no significant difference in the test and examination anxiety post-test mean score of male and female subjects exposed to problem-solving technique.

Table 3: Summary of t-test for male and female test and examination anxiety level (post-test) of experimental

\begin{tabular}{|l|l|l|l|l|l|l|}
\hline group \\
\hline Variables & No & X & SD & Df & t-cal & t- crit \\
\hline Male & 10 & 42.6 & 6.51 & 18 & 2.27 & 2.101 \\
\hline Female & 10 & 35.6 & 10.20 & & & \\
\hline
\end{tabular}


Table 3 showed that there is significant difference in post -test mean scores in test and examination anxiety of male and female in the experimental group. The $\mathrm{t}-$ cal 2.27 , t-critical $2.01 \mathrm{dfl} 8(\mathrm{P}<0.05)$. The $\mathrm{t}$ calculated is greater than t-critical, the hypotheses which states that there is no significant difference in test anxiety of male and female in the experimental group is rejected.

Hypothesis 4: There is significant difference in the academic performance post-test mean score of male and female subjects exposed to problem-solving technique.

Table 4: Summary of t-test for male and female Academic Performance (post-test) of experimental group

\begin{tabular}{|l|l|l|l|l|l|l|}
\hline Variables & No & $\mathrm{X}$ & SD & Df & t-cal & t_tab $_{\text {tal }}$ \\
\hline Male & 10 & 10.4 & 1.89 & 18 & -0.18 & 2.101 \\
\hline Female & 10 & 12.6 & 3.46 & & & \\
\hline
\end{tabular}

Table 4 above indicated that, the $\mathrm{t}-$ cal 0.18 , $\mathrm{t}$-critcal $2.101 \mathrm{df}=18(\mathrm{P}<0.05)$. Since the $\mathrm{t}$-cal $(0.18)$ is less than t-critical(2.101). This means that there is no significant difference in post -test mean scores in academic performance of male and female in the experimental group. Therefore the hypothesis isnotrejected.

\section{Discussion}

The resultsobtainned from this study indicate that problem solving technique therapy reduced the anxiety levels of students and improved the academic performance of experimental group. The reduction in test anxiety is in consonance with finding from previous studies by Menucha (2007), Kirkland (1996) and Okatahi (2006). These findings indicated that reduction of test anxiety could be attributed to the training program techniques which enabled the subjects in the experimental group to be better equipped and relaxed to face evaluative situations. Also, the counseling they received on how to prepare and write test and examination could have succeeded in dislodging the illogical thinking of subjects and replacing them with logical thinking; which therefore helped in reducing test anxiety to improve their academic grades.

After the problem-solving training technique, the mean score of anxiety level of experimental group dropped below while the academic grades increased as indicated on tables one, two and three.

The findings from hypotheses one showsa significant difference in test anxiety levels and academic performanceof experimental and control groups. Students exposed to problem-solvingtreatment technique had a higher post-test scores compared to their counterparts in the control group.

Furthermore, the result that indicated significant difference in the test anxiety levels of the male and female students was rejected. This shows that there is no significant difference in the test anxiety levels of experimental group. This is in support with the earlier view and findings of Barlow, (2002) who related test anxiety to family setting where parents exert pressure on their children in school to excel in their academic performance. Such high expectation often results into high test anxiety.

Therefore hypothesis one, two and threethat stated that there is no significant difference in the test anxiety levels and academic performance of students exposed to treatment technique and the control were rejected as shown in tables 1,2 and 3 .

In the same view, the reduction in test anxiety could be as a result of the problem-solving training which made use of five steps model method. Table 2 shows a significant difference in the level of academic performance of experimental and control. Since the experimental group succeeded inpracticing the processesin overcoming their test anxiety levels, it equally meant that they used the process to reduce their academic failure having gained some measures of self confidence in dealing with their failure situation. The findings corroborated Hassan and Okatahi (1990) which indicated that treatment technique could reduce worries and improved the academic performance of students.

In our society, the male students tend to suffer more of such pressures than their counterparts because they are perceived as future heads of families and bread winners. The female students are not under much pressure because they are expected to be dependents. This very high expectation placed on male children could explain why they are more test-anxious.

Eventually, no significant difference was established in academicgrades of male and female subjects of the experimental group. One explanation for this is that both male and female students went through the training of problem solving technique and the result on table 4 shows, $\mathrm{t}-$ cal $=0.18, \mathrm{t}$-critcal $=2.101$ with $\mathrm{df}=18$ $(\mathrm{P}<0.05)$. With $\mathrm{t}$-cal $=(0.18)$ lesser than $\mathrm{t}$-critical $(2.101)$ shows that the training session had an effect on subsequent examination grades of the students irrespective of gender. Agree with

\section{Conclusion}

It is evident from the findings of this study that experimental subjects exposed to problem-solving technique were able to demonstrate a healthy behavior pattern while the control group opened to placebo were unable to show any sign of improvement in their behaviour disorder of anxiety.it is important to note that anxiety is very hard to study. In humans it can be a subjective sense of unease, a set of behaviours, looking 
worried and anxious, fidgeting, or a physiological response originating in the brain and reflected in elevated heart rate and muscle tension. A close look at the t-test results showed that problem solving technique training effect was significant for all the variables except one. It is therefore believed that the psychological intervention taught students skills that could be used to manage their anxious moments.

\section{Recommendations}

It could be emphasizedupon thatthe counseling intervention on problem solving in stages which embraced all aspects of test taking have helped the experimental grouping reducing their test anxiety level.It is therefore recommended that students in secondary schools should be exposed to various techniques of studying. Guidance and Counselling units should include study skills program such as problem solving techniques to enable test anxious students to adjust during test and examination.

Parents and teachers should de-emphases the evaluative and competitive aspects of examination in schools. This will arouse less feelings of test-anxiety among students. More emphasis should be placed on informal assessment of students.

A replication of study with larger students will enable a wider generalization. Any effort to reduce test anxiety using problem solving intervention will yield positive result and increase students' academic performance.

Parents should not force their children to study subjects that do not comply with their ability simply because they want toimpose a career on them. They should respect the worth of the individual and consider the view of their children in selection of career.

Other intervention technique in counseling should be applied to enhance academic performance of students. livelihood.

Students should not be made to think that passing any examination is a matter of life and death for

Finally, it should be noted that early detection and understanding of reasons of academic failure may help curtail students to perform better if adequate guidance on improvement is provided sufficiently.

\section{References}

[1]. Adeyoju, C.A. (1989). The Relative Effectiveness of Cognitive Restructuring and Study Skills Training on the Adjustment to Academic Failure among a Group of Nigerian Students. Unpublished PhD Thesis, University of Ibadan, Ibadan.

[2]. Akinboye, J.O.(1982).Guidance and Counseling strategies for handling adolescents and youth problems. Ibadan: University Press.

[3]. Aremu, S. and Oluwole, D.A.(2000) Secondary school students academic performance. An evaluation of the predicting effectsof five variables. Ilorin Journal of Education.

[4]. Barlow, D.H. (2002). Anxiety and its disorders: The nature and treatment of anxiety and panic. (2 ${ }^{\text {nd }}$ edition). New York: Guilford.

[5]. Birenbaum, M and Pinku, P. (1997). Effects of Test Anxiety, Information Organisation, and Testing Situation on Performance on Two Test Format. Contemporary Educational Psychology, 22, 23-38.

[6]. Busari, A.O and Uwakwe, C.B (2001). The effect of stress inoculation training technique in the management of worry as a selfhandicapping strategy in intellectual performance. Niger Journal of Psychology.3(1),6-12.

[7]. Corey, G. (1995) Theory and Practice of Group Counselling. (4 $4^{\text {th }}$ Edition). Californica: Brooks/Cole Publishing.

[8]. Culler, R.E. and Holahan, C. (1980). Test Anxiety and Academic Performance: The Effect of Study- Related Behaviours. Journal of Educational Psychology, 72, 16-20.x

[9]. D’Zurilla, T.J. \& Goldfried (1971). Problem Solving and Behaviour Modification.Journal of Abnormal Psychology,78, $107-136$.

[10]. D'Zurilla, T.J. (1986). Problem- Solving Therapy: A Social Competence Approach to Clinical Intervention. New York:. Springe Press.

[11]. D’Zurilla, T.J. (1988). Problem- Solving Therapy. In K.S. Dobson (Ed), Handbook of Cognitive-behavioural therapies. New York: Guilford Press.

[12]. Hassan, T. and Okatahi, A. (1990) Relative Efficacy of Cognitive Restructuring and Impulsive Therapy in the treatment of Testanxiety. Journal of Research in Counselling Psychology.2, 102-109.

[13]. Karoly, P. and Kanfer. F.H. (1982). Self-management and behavior change. Theories to practice. Elmsford, New York: Pergamon Press.

[14]. Kirkland, M.U.(1996).Relieving anxiety in classroom examination. British journal of Educational psychology. 50, 53-60.

[15]. Mayer, R.E. (1994). Problem- Solving in V.S. Ramachadran (Ed) Encyclopedia of Human Behaviour, 1, San Diego: Academic Press.

[16]. McKeachie, W., Lin, Y. and Holinger, D (1986). Test Anxiety: Deficits in information processing. Journal of Educational Psychology.73,824.

[17]. Menucha, B. (2007).Assessment and instruction preferences and their relationship with test anxiety and earning strategies . Higher Education 53: 6, 749-757.

[18]. Mischel, M (1971). Introduction to Personality. Holt, Rinehart and Winston, Inc. New York. Pg 336.

[19]. Morakinyo, A. (1984). Relative efficacy of system desensitization, self-statement, monitoring and flooding on students test anxiety. Unpublished Ph.D. Thesis, Universityof Ibadan.

[20]. Okatahi, A.O.(2006). Reduction of Test Anxiety among secondary school student through study-skill training. Ahmadu Bello University Journal of Educational research and Development, 1 (3), 49-54

[21]. Olatoye, R.A and Afuwape, M.O (2003). Test anxiety as determinants of examination under achievement among some Nigerian secondary school students. Ibadan Journal of Education studies, 3 (182), 32-39.

[22]. Olorunfemi-Olabisi,F.A. (2010). Effects of Self-management and Problem-solving techniques on academic performance of secondary school students in Ondo State. Unpublished PhD Thesis, Adekunle Ajasin University, Akungba- Akoko. 
[23]. Osiki, J.O and Busari, A.O (2006). Effects of self-treatment, monitoring technique in the reduction of test anxiety among adolescent underachiever in Ibadan metropolis. The Counsellor 30(1) pg45-45.

[24]. Sarason, J.P. (1980) Casual attribution for success and failure: A multivariate investigation of dimensionality, information and consequences. Journal of personality38,704-718.

[25]. Sarason, and Mandler, (1972). A study of Anxiety and Learning. Journal of Abnormal and Social Psychology,47, 166-173.

[26]. Seipp, B.(1991) Anxiety and academic performance. A meta-analysis of findings. Anxiety Research 4, $27-41$.

[27]. Spielberg, C. D. (1979). Anxiety:Current trends in theory and research. New York Academic Press.

[28]. Sutherland, 1.(2002). Developing Problem-Solving expertise: The impart of instruction in a question analysis strategy.Journal of the European Association for Research on learning and instruction.12 (2), 155-187.

[29]. Yusuf, F.A. (2008). Effectiveness of Relaxation Technique in reducing examination anxiety among secondary school students in Nigeria. A paper presented at the Counselling Association of Nigeria Conference (CASSON) held at University of Ilorin between $18^{\mathrm{th}}-22^{\text {nd }}$ August 2008. 